\title{
Singularidades de un sistema de gobierno indígena del norte de México. El carácter interétnico y etnojerarquizado del sistema de cargos ódami
}

\author{
Eduardo R. Saucedo SÁnchez de Tagle \\ Instituto Nacional de Antropología e Historia, Centro San Luis Potosí (México) \\ eduardo_saucedo@inah.gob.mx \\ Íñigo GONZÁlEZ dE LA FuENTE \\ Depto. de Educación, Universidad de Cantabria \\ inigo_gonzalez@unican.es
}

Recibido: 5 de agosto de 2010

Aceptado: 18 de noviembre de 2010

\section{RESUMEN}

El presente texto se ubica dentro de los estudios antropológicos de los pueblos indígenas de la Sierra Tarahumara en el norte de México. Caracterizamos concretamente dos de las singularidades más importantes del sistema de gobierno de los ódami, las cuales consideramos distinguen tal sistema de muchos otros que han sido descritos profusamente en la literatura etnográfica, principalmente entre pueblos de tradición mesoamericana. En particular, señalamos por un lado la muy particular territorialidad ódami, con una división de la comunidad en dos mitades (los abajeños y los arribeños), división que incide directamente en el sistema de gobierno; y por el otro, destacamos el carácter interétnico y etnojerarquizado del sistema de gobierno, de tal manera que ciertas comunidades indígenas rarámuri, reconocen abiertamente su subordinación ante los principales cargos del gobierno de otro pueblo étnicamente distinto -los ódami-.

Palabras clave: Sistema de gobierno indígena; ódami; rarámuri; Norte de México.

\section{Singular Characteristics of a Native Government System Located in North Mexico. The Inter-ethnic and Ethno-hierarchized Organization of the}

\section{Odami's Sistema de Cargos}

\section{ABSTRACT}

This paper becomes part of native's anthropologic studies in Sierra Tarahumara, one of the bigger areas of North Mexico. Concretely, the authors talk about two of the most important singular characteristics of the Odami government system. Those characteristics are particularly different of the Mesoamerican ones, which have profusely been described in the ethnographic literature. First of all, the authors expose the very singular Odami territoriality. The main characteristic of this kind of phenomenon is that the community is divided in two halves: the «abajeños» and the «arribeños». This division transforms the Odami government system organization. Secondly, the authors emphasize the inter-ethnic end ethnohierarchized Odami organization, in the way of a native people -the Raramuri-is clearly subordinate to the government hierarchy of another native people -the Odami-.

Key words: Native government system; Odami; Raramuri; Northern Mexico.

Sumario: 1. Introducción. 2. El escenario y los actores. 3. Sistema de gobierno y normatividad ódami. 4. El carácter interétnico y etnojerarquizado del sistema de gobierno ódami. 5. Referencias bibliográficas. 


\section{Introducción}

La región a la que antropólogos, historiadores y otros especialistas han denominado norte de México ${ }^{1}$ es un territorio muy específico del actual México indígena. Caracterizada por abarcar un enorme territorio, la región ha sido poco investigada por las ciencias sociales, especialmente si se la compara con el antiguo territorio mesoamericano, el centro y/o el sur del país, en torno al cual se ha focalizado la atención de la mayoría de investigaciones. Lo extenso del territorio norte, lo extremo de su clima y su geografía - plena de montañas, desiertos, barrancos y valles-, y la feroz y creciente violencia social de la que ha sido escenario durante los últimos años, son también factores que han dificultado y acentuado enormemente la falta de investigación.

La mayoría de científicos sociales presenta el norte de México como parte de un vasto «corredor cultural» denominado La Gran Chichimeca, el cual enlazaba desde tiempos prehispánicos los actuales territorios del suroeste de los Estados Unidos, el norte de México, y la frontera septentrional de Mesoamérica (Di Peso 1974; Braniff 1999, 2000a, 2000b). Según este planteamiento, La Gran Chichimeca representa tan solo un referente geográfico y cultural que carece de fronteras claramente definidas, y que se caracteriza, sobre todo, por sus conexiones con otros territorios. Así, esta extensa región puede ser considerada como un puente entre puentes o bien, un corredor entre otros corredores, que en distintas épocas y con diferentes grados e impacto, ha mantenido un permanente diálogo con muchas otras regiones del continente americano.

Y es precisamente este último aspecto el que nos interesa resaltar sobre la Sierra Tarahumara: se trata de una región relevante en la medida en que forma parte de un territorio que une, histórica y culturalmente, el suroeste norteamericano con el norte de México y con Mesoamérica; una región en donde actualmente se expresan abierta y ferozmente las más profundas contradicciones del sistema político y económico.

Paralelamente, la historia oficial mexicana, la identidad nacional, y en general, el imaginario sobre los mexicanos y lo mexicano, están fuertemente enraizados y relacionados con símbolos y alusiones a culturas indígenas de Mesoamérica. Se trata de una construcción de la indianidad mexicana en la cual los pueblos indígenas del norte del país apenas han tenido lugar. Desde siempre excluidos, estos pueblos han sido además profundamente estigmatizados por los distintos poderes y gobiernos con los que, a través del tiempo, han interactuado. Asimismo, su territorio ha sido históricamente un lugar conflictivo y violento, indeseable pero necesario a los intereses del gobierno en turno. En tiempos prehispánicos, por ejemplo, los habitantes del imperio mexica y de otras áreas de Mesoamérica se referían a los pueblos del norte con el despectivo nombre de chichimecas (linaje de perros), y los concebían como pueblos bárbaros e incivilizados. Tiempo después, desde mediados del siglo XVI y hasta el fi-

1 La región abarca un poco más de la tercera parte del país, por lo que vale la pena reparar un instante sobre sus notables dimensiones. México cuenta con un territorio de $1.964 .375 \mathrm{~km}^{2}$, divididos política y administrativamente en 31 estados y un Distrito Federal. El norte de México concentra siete de los estados más grandes del país, y entre ellos destaca el estado de Chihuahua, escenario de este trabajo, el cual cuenta con una superficie de $247.455 \mathrm{~km}^{2}$, es decir, casi la mitad del territorio de España. 
nal del periodo colonial, conquistadores, evangelizadores y colonizadores conocieron de cerca el trato y la guerra con los pueblos indios del norte de México, en donde, según sus propias palabras, «habitan las naciones indígenas más bárbaras, salvajes y aguerridas de todo el Nuevo Mundo» ${ }^{2}$. Pueblos que les ofrecieron una feroz e incansable resistencia, a través de constantes rebeliones, sublevaciones y correrías, que se prolongaron hasta el final de la colonia. De igual forma, México y EE.UU. declararon a comienzos del siglo xix una guerra abierta en contra de diversos pueblos de la región (yaquis, comanches, apaches, entre otros), a quienes se persiguió y se deportó masivamente, al tiempo que se les arrebató muchos de los territorios que habían logrado conservar a lo largo del periodo colonial.

A ese oscuro panorama, hay que agregarle además, desde la segunda mitad del siglo xx hasta la fecha, la creciente ola de violencia resultado de la infiltración del narcotráfico y el crimen organizado en las bases del sistema político y económico mexicano, la cual se ha incrementado en frecuencia, brutalidad e impunidad en los últimos años, concentrándose justamente en el norte de México.

$\mathrm{Y}$ es precisamente en ese contexto donde debe ubicarse el actual estudio antropológico de los pueblos indígenas de la Sierra Tarahumara, y la caracterización del sistema de gobierno ódami que aquí presentamos. El trabajo está organizado de la siguiente manera: en el primer capítulo, presentamos una panorámica de la Sierra Tarahumara y de la cultura del pueblo ódami. Seguidamente, damos una visión general sobre los «sistema de cargos» en México para terminar concretando una breve caracterización y análisis del sistema de gobierno y la normatividad social ódami. Y finalmente, concluimos destacando algunas singularidades la cuales, consideramos, distinguen al sistema de gobierno ódami de muchos otros que han sido descritos profusamente en la literatura etnográfica, principalmente entre pueblos de tradición mesoamericana. En particular, destacaremos dos notables singularidades: 1) la muy particular territorialidad ódami, y su reflejo en el ámbito de acción del sistema de gobierno; y 2) el carácter interétnico y etnojerarquizado del sistema de gobierno.

\section{El escenario y los actores}

La llamada Sierra Tarahumara es una porción de la Sierra Madre Occidental que atraviesa el sur y suroeste del estado de Chihuahua, entre los 26 y $30^{\circ}$ de latitud norte, y los 106 y $109^{\circ}$ de longitud al oeste del meridiano de Greenwich. Con más de 75.910 $\mathrm{km}^{2}$ entre ambos lados de las montañas, la Sierra Tarahumara comprende 18 de los 67 municipios en los que se divide el vasto territorio chihuahuense, además de algunos municipios colindantes de los estados de Sonora y Sinaloa.

En términos territoriales y demográficos, la Sierra Tarahumara es la región indígena más grande del norte de México, y en sus montañas y barrancos actualmente habitan cuatro pueblos indígenas, de los cuales los tarahumaras (o rarámuri en su propia lengua) son los más numerosos y conocidos. Demográficamente, los tarahumaras

2 De una carta del padre Joseph Neumann al reverendo padre de la Compañía de Jesús provincial de la provincia de Bohemia, 15 de abril de 1724 (apud. González 1991: 22-34). 
suman poco más de 75.000 individuos, seguidos por unos 6.000 ódami o tepehuanes del norte, 1.500 guarijíos, y poco menos de 1.000 pimas $^{3}$. Los pueblos indios de la Tarahumara comparten el territorio serrano con unos 114.000 individuos no indígenas o «mestizos», quienes de hecho conforman la mayoría de los habitantes de la región, y con quienes los pueblos indígenas han mantenido una histórica relación conflictiva por el control y manejo del territorio y los recursos naturales y económicos.

Entre las particularidades geográficas de la región destacaremos que, debido a la convergencia de altas montañas y profundos barrancos, y al resultante contraste ecológico entre ambos espacios, existe una enorme diversidad ambiental, la cual se manifiesta en términos del clima, la fauna y la vegetación. En distancias relativamente cortas confluyen marcadas diferencias de alturas, pendientes, temperaturas y caídas de agua. Las distintas elevaciones - que van desde los 3000 m.s.n.m. en los picos más altos hasta los 300 m.s.n.m. en el fondo de algunas barrancas-, propician diversos niveles de humedad y temperatura, los cuales producen a su vez diferentes períodos para los ciclos agrícolas y de recolección. Debido a que, tecnológicamente hablando, la mayor parte de la Sierra no es cultivable, las escasas zonas propicias para sembrar maíz - la gramínea básica para la vida-, se encuentran distribuidas en pequeñas porciones dispersas a lo largo de arroyos y otros aluviones, separadas por distancias que pueden ir desde uno hasta veinte kilómetros, atravesados por cumbres y barrancos (Kennedy, 1970: 54-59). Paralelamente, las mejores tierras agrícolas de la región, ubicadas en los valles pluviales y las planicies de la vertiente oriental de las montañas -las cuales albergaban la mayoría de la población prehispánica-, son habitadas actualmente por comunidades no indígenas.

Ecológicamente, la región se divide en tres sub-regiones, y sólo en dos de ellas se concentra el grueso de la población indígena, a saber: en las tierras altas del macizo central, de cumbres frías y boscosas, con enorme riqueza forestal, y donde el termómetro registra algunos de los inviernos más fríos de todo México; y en la tierra caliente de las profundas barrancas del oeste, hacia donde descargan multitud de arroyos y donde las temperaturas en verano superan regularmente los 40 grados centígrados ${ }^{4}$. Estas particularidades ambientales han propiciado algunas de las características más señaladas en la vida de los pueblos indígenas de la región, tales como su movilidad estacional - cumbres en verano y barrancos en invierno- a manera de un ajuste económico/ambiental, adecuado a la tecnología que estos pueblos poseen. Dicha movilidad permite cultivar en ciclos sustancialmente diferentes (en las partes altas se puede sembrar por ejemplo trigo o avena), además de la recolección de diferentes productos en ambos nichos ecológicos.

Es de subrayar que, hoy en día, la Sierra Tarahumara se caracteriza por un patrón de población indígena diseminada a lo largo de todo su territorio, en asentamientos generalmente menores al centenar de habitantes, lo cual se vincula estrechamente con las características fisiográficas y ecológicas de la región (Serrano 2006). De igual modo, la

\footnotetext{
3 Cifras del «Conteo de población 2005» realizado por el Instituto Nacional de Geografía, Estadística e Informática (INEGI).

4 Para una completa caracterización geográfica y ecológica de la Sierra Tarahumara véase: Pennington 1969; Bye 1976; Schmidt 1976; Hillerkuss 1992.
} 
mayoría de las comunidades indígenas de la región están hoy estructuradas, justamente, a partir de diversas unidades o centros denominados como pueblo, «en el que se localiza el templo o centro ceremonial, y a los alrededores los ranchos y rancherías dispersas que forman parte del territorio del pueblo. [...] Es el lugar donde se reúnen para realizar las asambleas dominicales entre las autoridades indígenas y la comunidad, impartir justicia, y para llevar a cabo sus fiestas» (González et al. 1994: 30-34).

De la misma manera, al pueblo se le sobreponen otras formas de organización no indígenas, tales como los municipios y los ejidos ${ }^{5}$, lo cual crea un complejo entramado y la yuxtaposición de distintas demarcaciones territoriales y jurisdiccionales. Por ejemplo, además de municipios, pueblos y ejidos, existen también secciones y comisarías municipales, así como distritos judiciales y electorales. Tal situación, además de dificultar el registro y el análisis empírico, también implica que las estructuras políticas indígenas se vean continuamente forzadas a competir por atribuciones, en crecientes condiciones de desventaja, contra el conjunto de dependencias municipales, estatales y federales, ante el cual resultan comúnmente excluidas.

Finalmente, consideramos necesario en este punto ofrecer una panorámica específica sobre la historia y la cultura ódami, la cual brinde soporte al análisis de su sistema de gobierno ${ }^{6}$.

La palabra «tepehuan» aparece por primera vez entre los cronistas de la conquista entre finales del siglo XVI y principios del XVII, y según algunos autores, el término proviene de la raíz náhuatl tepetl, que significa cerro, más la partícula posesiva hua, traduciéndose como «gente de los cerros» (Pennington 1969). En todo caso, no existe un consenso al respecto. A pesar de que los documentos históricos refieren que los «tepehuanes» eran el pueblo indígena más numeroso de lo que hoy conocemos como el norte de México, la cual incluso se dice sometía y recibía tributos de otros pueblos vecinos como los acaxees, los tepehuanes están actualmente constituidos sólo

5 El ejido es una figura jurídica heredada de la Revolución Mexicana. Se basa en la atribución de una parcela pequeña a los campesinos, donde cada uno de ellos la usufructúa y la puede heredar, pero que, hasta las reformas al artículo 27 de la constitución, promulgadas en 1992 (durante el periodo presidencial de Carlos Salinas de Gortari) no se podía vender ni rentar. Por «ejido» se entiende tanto la parcela individual, como una determinada «zona ejidal», que depende de las mismas autoridades. Algunas veces, como en el caso de la Sierra Tarahumara, se dota colectivamente a un ejido de amplias zonas de bosques o pastos. Los beneficios que se obtienen por la explotación o renta de esas tierras se reparten, teóricamente, entre todos los «derechohabitantes» o ejidatarios. Dicha estructura, su manejo y funcionamiento, resultan en muchos sentidos ajenos al pensamiento indígena, y es precisamente esa incomprensión de las leyes agrarias y comerciales -junto con otros factores-, lo que favorece que ese sistema se preste a robos y corrupción, así como a la manipulación, despojos y presiones sobre las comunidades indígenas, ya sea directamente o a través de los aserraderos y las instancias técnicas que median en el proceso de extracción de la madera. En términos generales, en la Sierra Tarahumara, los funcionarios ejidales se dedican a administrar la explotación del bosque, y sus intereses son esencialmente económicos y ajenos a las comunidades indígenas. Asimismo, la explotación forestal que se ha practicado en la zona, por casi un siglo, lejos de estar basada en un uso racional de los recursos madereros, ha sido rapaz y depredadora, y ha deforestado, erosionado y contaminado intensamente enormes superficie.

6 Los datos etnográficos que a partir de aquí presentamos son el resultado del trabajo de campo que el investigador Eduardo R. Saucedo ha realizado entre los años 1998 y 2008, en distintas comunidades ódami, rarámuri y mestizas de la región, principalmente en los municipios de Guadalupe y Calvo, Guachochi, Bocoyna y Batopilas. Durante esos diez años se realizaron temporadas de entre 40 a 65 días al año, distribuidas en uno o dos momentos distintos del ciclo anual. Un dato a considerar es que las investigaciones se han centrado en su mayoría en el pueblo rarámuri, mientras que el trabajo con los ódami ha sido más reciente, lento y difícil. 
por dos pequeños grupos, geográficamente distantes y culturalmente diferenciados, situados en la proximidad de lo se cree alguna vez fueron las fronteras norte y sur de su territorio original (Reyes 2004): los «tepehuanes del norte» y los «tepehuanes del sur». Las diferencias que existen entre ellos se manifiestan con claridad en su lengua, su indumentaria, su organización social, su religión y sus ideas y creencias sobre el mundo; así como en otros aspectos materiales y abstractos de su vida y su cultura.

Los tepehuanes del sur ( $o^{\prime}$ dam y audam en su propia lengua) habitan en porciones de la Sierra Madre Occidental, al sur del estado de Durango y en pequeñas áreas del norte de Nayarit. Ellos comparten ciertos elementos históricos y culturales con otros pueblos indígenas de esa zona, como los coras y los huicholes. Al tiempo que los ódami o tepehuanes del norte, principales protagonistas de este texto, habitan más al norte de la propia Sierra Madre Occidental, en rancherías dispersas entre cumbres y barrancos de la llamada Sierra Tarahumara, al extremo sur del estado de Chihuahua. Los ódami también comparten aspectos de su historia y su cultura con algunos pueblos vecinos, particularmente con los tarahumaras o rarámuri, y en menor medida, con los guarijío y los pimas.

Los ódami habitan actualmente cinco de las 12 secciones en las que se divide el municipio de Guadalupe y Calvo, el más meridional del estado de Chihuahua. Una región interétnica cohabitada también por núcleos de población rarámuri y mestiza. Sin embargo, sólo en dos de esas secciones municipales se concentra el grueso de la población ódami, a saber: Baborigame y Nabogame, las cuales deben su nombre a los dos pueblos que representan los principales centros políticos y religiosos ódami ${ }^{7}$.

A diferencia de sus vecinos rarámuri, los ódami han sido generalmente desdeñados por la literatura etnográfica. Esa falta de estudios es también evidente si se les compara con los tepehuanes del sur, sobre los cuales existe hoy un número considerablemente mayor de publicaciones ${ }^{8}$. Los pocos textos etnográficos accesibles sobre los ódami resultan, por diversos motivos, insuficientes para darnos una visión completa y actual de su cultura (Lumholtz 1981; Mason 1948; Pacheco 1997; Molinari y Nolasco 1995; Pennington 1969; Saucedo 2003, 2005, 2008, s/f.). En este sentido, el sistema de gobierno ódami representa tan sólo uno de los muchos aspectos sobre el cual no existen aún publicaciones etnográficas específicas.

7 Existe también, según el censo INEGI 2000, población ódami en los municipios chihuahuenses de Balleza (284 personas), Guachochi (120), Batopilas (112), entre otros. Pero de un total de 6.178 hablantes de lengua «tepehuana» reportados en Chihuahua, 5.133 de ellos viven en el municipio de Guadalupe y Calvo. Las autoridades del municipio dividen los $9.010 \mathrm{~km}^{2}$ de su territorio en doce secciones políticoadministrativas que son: Guadalupe y Calvo, Nabogame, Baborigame, San Juan Nepomuceno, Mesa de San Rafael, Atascaderos, Turuáchi, San Julián, Dolores, Santo Domingo, Tohayana y Calabacillas. Sin embargo, al parecer sólo existe una cantidad significativa de población indígena en las primeras seis. Los principales pueblos indígenas del territorio ódami son: Baborigame -el cual constituye de hecho la principal sede del gobierno indígena-, Nabogame -mismo que ha venido poco a poco perdiendo su importancia religiosa y política-, Llano grande, Santa Rosa, Cinco Yagas, Tuáripa y Coloradas de la Virgen; éstos dos últimos, de población predominantemente tarahumara. Muchos de estos pueblos son también habitados por población mestiza, la cual representa la mayoría de los habitantes de la región, ocupando unas tres cuartas partes del territorio municipal.

8 Una panorámica completa de la bibliografía etnográfica sobre los tepehuanes del sur en particular, y de investigaciones históricas sobre los tepehuanes en general, puede encontrarse en: Reyes 2004 y Jáuregui 2005. 


\section{Sistema de gobierno y normatividad social ódami}

Resulta necesario hacer referencia explícita a la amplia cantidad de estudios antropológicos que existen sobre los sistemas de cargos, tema que representa uno de los marcos privilegiados a través de los cuales los antropólogos han investigado la normatividad indígena en el centro y sur de México. Desde la segunda mitad del siglo xx y hasta la fecha, la literatura sobre el tema es extensa, aunque, como se ha destacado, se trata de investigaciones desarrolladas, básicamente, entre pueblos de tradición mesoamericana (Aguirre Beltrán 1953, 1967; Cancian 1966, 1989, 1996; Carrasco 1990; Korsbaek 1996; Medina 1995; Castilleja y Cervera 2003; Jáuregui 2003; Smith 1981; Chance y Taylor 1987; Greenberg 1987; Sandoval 2000; Romero 2002). En este contexto, existen trabajos que reseñan puntualmente los principales ejes de la discusión teórica, a la vez que clasifican los distintos modelos explicativos que con el tiempo han surgido sobre los sistemas de cargos, por ejemplo, entre aquellos que ponen énfasis en la nivelación, la estratificación o la redistribución social y económica (Romero 2002).

Consecuentemente, tampoco existen estudios comparativos de los sistemas de cargos entre pueblos de Mesoamérica y del norte de México. No obstante, es preciso aclarar que, en el caso de los ódami -como en el de muchos otros pueblos del norte-, el conocimiento científico que poseemos sobre ellos se encuentra aún muy incipiente. En términos generales, no existen etnografías generales ni mucho menos específicas que nos permitan hacer comparaciones, generalizaciones, y análisis más amplios de este u otros temas.

Los antropólogos que trabajamos con los pueblos del norte de México estamos atados a la doble tarea de, primero, recopilar un corpus básico de información que nos permita, ya en un momento posterior, dialogar extensamente con Mesoamérica y con los propios pueblos indios del norte.

El sistema de gobierno tradicional de los ódami, al igual que otros elementos de la actual cultura indígena, puede definirse a través de la síntesis realizada entre patrones introducidos por sociedades ajenas y hegemónicas durante más de cinco siglos, junto a la particular apropiación que los ódami han hecho de ellos. Respecto a las «autoridades» o «jefes» indígenas de la Sierra Tarahumara, los misioneros jesuitas a finales del siglo XVII escribían lo siguiente:

«estas naciones, en su gentilidad, no reconocen sujeción a otro. Gobiérnanse por familias, de suerte que el más anciano de ellas es a quien los demás reconocen, no con superioridad de dominio sino por vía de respeto, semejante al que tiene un mozo a otra persona de más edad. Éste es el origen de la poca sujeción al Padre [cristiano] y a sus gobernadores y alcaldes que se procuran poco a poco entablar. [...] Los Padres pensaron que para impedir estas cosas [peleas, desórdenes y borracheras], y para instaurar las costumbres cristianas, de todas las formas posibles se les obligaría [a los indios] a congregarse en pueblos, poniéndoles gobernadores y capitanes de su misma nación - aquellos que gozaran de mayor autoridad entre los suyos-, bajo cuyas órdenes los demás obedecieran más fácilmente. [...] Los gobernadores indígenas, autoridad suprema, impartían la justicia; los soldados, bajo la autoridad de los capitanes, mantenían el orden y la seguridad; los fiscales vigilaban la limpieza de la iglesia 
y se encargaban de los enfermos; los mayoras, especie de policías de costumbres, detectaban a las parejas no casadas; los temastianes enseñaban el catecismo y dirigían la oración en ausencia de los misioneros» (Ronáldegi, apud, Velasco 1983: 32-33).

En la actualidad, la estructura formal del gobierno indígena de la región se basa justamente en las jerarquías cívico-religiosas, o «sistemas de cargos», introducidos por los misioneros europeos durante la colonia. Y a pesar de las innumerables rebeliones indígenas, del fracaso generalizado del sistema de pueblos, de la insubordinación oculta hacia las autoridades coloniales, y del poco control efectivo que éstas lograron sobre los habitantes de la región, resulta sin duda notable que la organización introducida por jesuitas y franciscanos haya sido tan ampliamente adoptada, y que siga hoy en vigor a lo largo de la Sierra Tarahumara y buena parte del noroeste de México. No en todos los sitios se conservan todos los cargos, pero prácticamente todos siguen de una u otra forma en uso y, salvando algunas diferencias formales, sus atribuciones son básicamente las mismas.

La normatividad social ódami, y más concretamente, la organización del gobierno tradicional en el pueblo de Baborigame (el principal centro político y religioso), presentan una serie de elementos particulares. Un rasgo distintivo de esa forma de organización es que el pueblo de Baborigame concentra, en torno a la figura del capitán general o moyi (máxima autoridad ódami), una serie de pueblos que, a pesar de contar cada uno con su propio gobernador, reconocen en Baborigame y en su capitán general, respectivamente, el principal centro político-religioso de su territorio y la máxima figura de autoridad y representatividad indígena. Ejemplo de esta situación son los pueblos de Nabogame 9 , Llano Grande, Cinco Yagas, Santa Rosa, Tuáripa y Coloradas de la Virgen; los dos últimos, habitados predominantemente por tarahumaras y una mínima cantidad de mestizos. En ninguna otra parte de la Sierra Tarahumara o del norte de México existe un caso similar, en el cual un pueblo indígena -y su estructura de gobierno- reconozca abiertamente su subordinación a la autoridad de otro pueblo indígena, tal como en este caso, en donde los gobernadores tarahumaras de los pueblos de Tuáripa y Coloradas de la Virgen se ubican jerárquicamente por debajo del capitán general ódami de Baborigame.

La actual estructura formal del gobierno ódami se basa, como se ya se señalaba, en el sistema de cargos, el cual está hoy constituido como recoge la Figura 1.

Ahora bien, antes de presentar las principales características de cada una de esas autoridades, es necesario hacer un breve paréntesis para introducir un rasgo importante de la estructura social ódami, el cual evoca aspectos de lo que ciertos autores han denominado sistema de mitades o, en algunos casos, «organizaciones dualistas» (Lévi-Strauss 1995). Dicho elemento radica en la división que los ódami hacen de la población indígena en dos partidos, los coijarkami (abajeños) y los tikarkami (arribeños), sobre la cual se funda buena parte del sentido y el desarrollo de las principales

\footnotetext{
9 Nabogame es un caso particular, pues a pesar de que es el único pueblo -además de Baborigame- que cuenta también con su propio capitán general, la persona que ocupa ese cargo, y la comunidad ódami de ese y otros pueblos, reconocen abiertamente la superioridad del capitán general de Baborigame. Desde la década de los 40 y hasta la fecha, la organización tradicional y el gobierno indígena en Nabogame se han ido deteriorando y abandonando paulatinamente.
} 
Figura 1: Sistema de cargos ódami

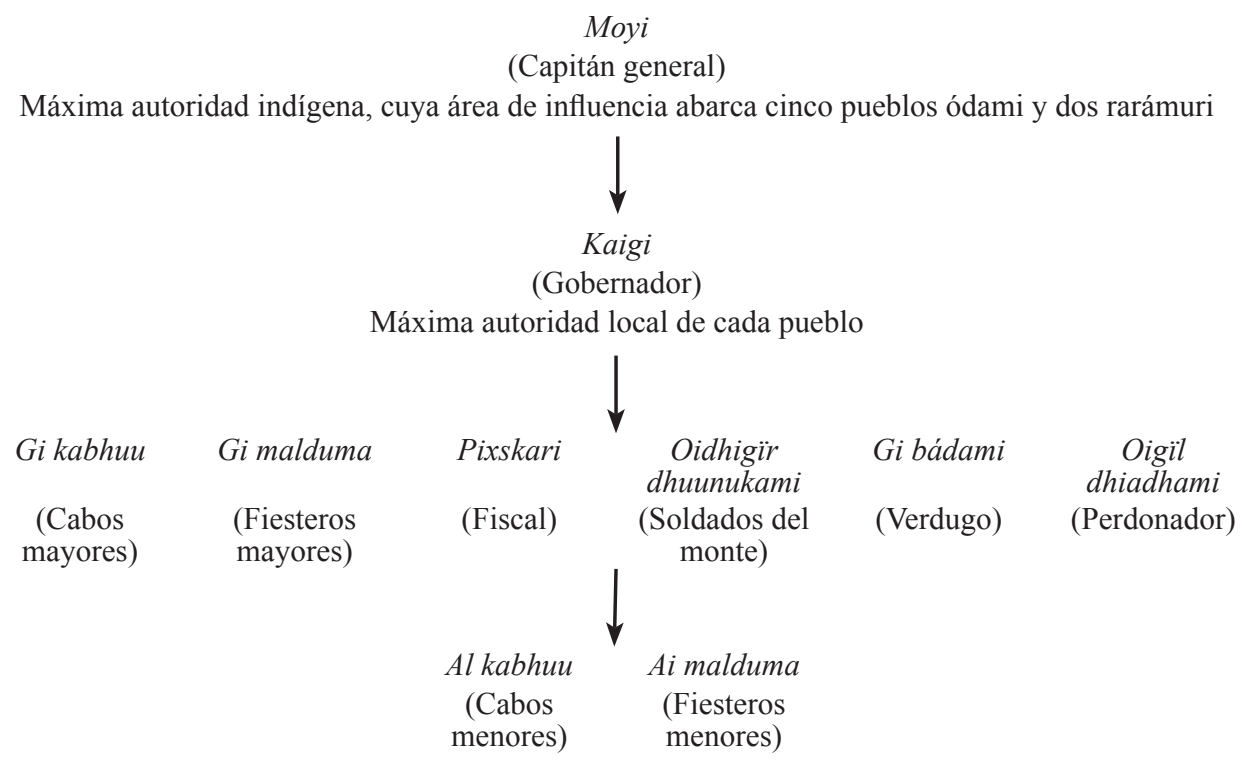

celebraciones comunitarias ${ }^{10}$. Es necesario precisar que, aunque la actual organización social ódami no está basada en un sistema «dualista» o de «mitades» como tal, existen notables coincidencias entre ciertos elementos que caracterizan ese tipo de organizaciones y aquellos que en el caso de los tepehuanes del norte se aluden para la división de la comunidad en dos bandos (Ibíd.). Existen dos criterios a los que los ódami aluden para el establecimiento de la división entre abajeños y arribeños, ambos relacionados con elementos geográficos. El primero -y más generalizado- representa el área central del pueblo de Baborigame como un plano relativamente circular u ovalado, dividido por un diámetro que cruza de la mitad de la puerta de la iglesia católica hacia el norte -territorio arribeño-, y de la otra mitad hacia el sur-territorio de los abajeños-, frente a lo cual estaríamos ante una representación similar a la de una estructura dualista de tipo diametral (Ibíd.: 167). El segundo de los criterios enfatiza como referente el arroyo que cruza el poblado, distinguiendo a los que viven aguas arriba o arribeños, de los que habitan aguas abajo o abajeños, hecho que nos remite también a una forma de dividir y nombrar a las mitades que ha sido ampliamente documentada entre distintas culturas de América del norte y del sur (Ibíd.).

Los diversos ranchos y rancherías que rodean al pueblo de Baborigame se asumen igualmente como parte de alguno de los dos bandos, dependiendo del lado en el que

10 En la Semana Santa, por ejemplo, los abajeños y los arribeños se constituyen como dos grupos ceremoniales opuestos, integrados a su interior de manera equivalente, a partir de cuya interacción y confrontación se da sentido a las principales actividades de la fiesta: por ejemplo, carreras de bola y de aros, procesiones, peleas y danzas rituales, tesgüinadas, etc. (Saucedo s/f). 
estén ubicados. Asimismo, para la celebración de Semana Santa y otras fiestas los habitantes del pueblo de Nabogame, y de las rancherías aledañas implementan, con base en idénticos criterios, esta misma división ${ }^{11}$.

Se destaca que, fuera del contexto de la fiesta, la división entre abajeños y arribeños pareciera no tener, en general, mayores implicaciones en la organización social. Los ódami no recuerdan, por ejemplo, que haya existido nunca la prescripción o la prohibición de casarse con personas de alguno de los bandos, y no existen formas de organización del trabajo, ni deberes o derechos sociales específicos que se relacionen con esta división. En el desarrollo de la vida cotidiana no hay tampoco un trato diferenciado entre los sujetos pertenecientes a una u otra mitad. De igual forma, no existe evidencia alguna de que existan otro tipo de representaciones y formas de organización que comúnmente aparecen ligadas entre sí en los llamados sistemas dualistas o de mitades, tales como el dualismo diametral, el dualismo concéntrico y las triadas (Lévi-Strauss 1995: 180). Entonces, aunque desde un punto de vista pragmático, la actual división ódami entre abajeños y arribeños no cumple aparentemente una función de gran trascendencia a nivel de la organización social, es preciso remarcar que, ante la visible pérdida y debilitamiento de la cultura tradicional, esta forma de organización se liga ampliamente con la reproducción cultural, la afirmación de la identidad étnica, y con la legitimación de las instituciones indígenas.

Ya específicamente, en lo concerniente al sistema de gobierno, la división entre abajeños y arribeños tiene importantes implicaciones. Por un lado, la comunidad ódami afirma que la tradición dicta que el capitán general de Baborigame debe ser siempre un arribeño, y tener, necesariamente, a un «suplente» $\mathrm{o}$ «segundo» abajeño ${ }^{12}$. Al mismo tiempo, se señala que es muy importante procurar un equilibrio en la distribución del cargo de gobernador, y que en Baborigame y en algunos otros pueblos del territorio, el gobernador principal debe ser siempre, alternadamente, un abajeño y un arribeño, intercalados en periodos de un año. Ahora bien, aunque este último precepto no se cumpla en ocasiones, el hecho de que exista y se enfatice es sin duda significativo ${ }^{13}$.

Por último, es necesario señalar que -como se verá en las siguientes páginaslos cargos más importantes del gobierno tradicional son ocupados generalmente por hombres mayores de 30 años, bien establecidos en la comunidad y con probada experiencia en otros cargos. Usualmente no hay hombres ancianos ocupando posiciones de gobierno, ya que se dice que «ya cumplieron» y también porque resulta necesario

11 Otros pueblos pertenecientes al área de influencia de Baborigame (es decir, que reconocen como máxima autoridad indígena al Capitán General ódami de Baborigame, por encima de su propio gobernador), y que también implementan en ciertas fiestas la división entre abajeños y arribeños son: Santa Rosa, Llano Grande, Cinco Yagas, Coloradas de la Virgen y Tuáripa, éstos dos últimos, como ya se señaló, compuestos por población tarahumara.

12 Un dato interesante es que la gente perteneciente a los ranchos y rancherías abajeñas de Baborigame ha intentado cambiar esa situación y proponer que también se nombre, alternadamente, un capitán general abajeño -junto con su respectivo «suplente» arribeño-. Sin embargo, los arribeños, al ser numéricamente mayoría, no han permitido que tal propuesta prospere.

13 Como se verá más adelante, la estructura de cargos enunciada líneas arriba funciona también bajo la lógica de dividir, equitativa y alternadamente, algunos de los principales cargos del gobierno entre arribeños y abajeños. 
cierto vigor físico para ejercer el liderazgo ${ }^{14}$. Sin embargo, todos los ancianos de la sociedad permanecen activos hasta hallarse físicamente incapacitados.

Pasamos a describir a continuación algunas de las características y funciones de los principales cargos del gobierno tradicional ódami.

El Moyi (Capitán General) es la máxima autoridad. Este cargo sólo puede ser ocupado por un hombre, de preferencia mayor de 30 ó 40 años, el cual debe contar con un enorme reconocimiento y prestigio por parte de la comunidad, principalmente, en lo que se refiere a su vocación de servicio a los demás, y a su conocimiento y preocupación por la cultura y la identidad ódami. De igual forma, y aunque no se dice abiertamente, es importante que la persona sea considerada como alguien con cierto grado de preparación e inteligencia -que sepa leer y escribir-. El tiempo de duración del cargo es de tres a cuatro años y está sujeto -al igual que cualquier otro cargo del gobierno tradicional- al buen desempeño que a los ojos de la comunidad tenga la persona en turno (por ejemplo, hay capitanes generales que han durado hasta 18 años en el puesto).

Su elección se realiza por consenso de la comunidad, es decir, por todos los habitantes de Baborigame y las rancherías aledañas. La elección del capitán general no tiene fecha fija. Algunos ódami de edad avanzada dicen que el día del Corpus Christi era antes utilizado para realizar ese acto; sin embargo, en la actualidad, puede también efectuarse el 24 de octubre o el 6 de enero, fechas que coinciden con dos de las más importantes fiestas ódami en Baborigame. Tanto el inicio de actividades de un nuevo capitán general como las «pláticas» previas que sostiene la comunidad ódami sobre quién puede ser el mejor candidato para ocupar dicho puesto, se llevan a cabo en el convento, una construcción anexa al templo católico en la cual se desarrollan las principales actividades político-religiosas ódami.

Algunas de las principales funciones del capitán general son: representar dentro y fuera del territorio indígena a la comunidad ódami y rarámuri del área de influencia de Baborigame; impartir justicia cuando la comunidad se lo demande; proteger el patrimonio cultural indígena y la paz social; visitar los distintos pueblos de su área de influencia para ayudar a los gobernadores indígenas locales a solucionar problemas y gestionar apoyos en dependencias gubernamentales y no gubernamentales -aunque se dice que esta función ya no se realiza más-, así como estar presente en el cambio de cada uno de esos gobernadores; preocuparse por impulsar la realización y el buen desarrollo de las principales festividades y las asambleas dominicales, así como dar «consejos» a los gobernadores y a las personas que ocupan otros cargos del gobierno tradicional, al igual que a la comunidad indígena en general; ser un modelo de conducta a seguir, especialmente, por los niños y los jóvenes de la comunidad.

14 No obstante, frente a las decisiones o conflictos más importantes que enfrenta la comunidad, se brinda especial atención a la voz y los consejos de algunos ancianos reconocidos por su amplia «sabiduría» y prestigio, aunque la edad en sí misma no brinda de manera directa este estatus de «sabio». Muchos de esos ancianos reconocidos por la comunidad han ocupado u ocupan posiciones importantes en la estructura social (como algún cargo del gobierno indígena o el ejercicio de la medicina tradicional), aunque no existe ningún patrón o prescripción cultural al respecto. 
De igual modo, se dice que hace mucho tiempo el capitán general tenía que encargarse de velar por el bosque -tanto por situaciones relacionadas con la explotación y el repartimiento de las tierras del ejido, como por los incendios forestales-, y visitar los pueblos, ranchos y rancherías donde hubiera habido alguna pelea o problema importante entre la población, tratando de conciliar las partes en conflicto (este último trabajo recae actualmente en los comisarios).

Por último, la gente que ha ocupado u ocupa este puesto opina que lo más difícil de cumplir con éste y otros cargos - como el de gobernador-, es tener que descuidar la familia y ciertas actividades ligadas a la subsistencia cotidiana, pues al ocupar dichos cargos se adquieren responsabilidades tales como viajar por varios días y semanas a rancherías distantes o ciudades como Chihuahua, Parral, Durango, Ciudad de México, etc.; además de que, usualmente, en tales viajes no se cuenta con ningún tipo de apoyo económico, por lo que los pasajes, la comida y el hospedaje deben ser cubiertos muchas veces por las propias autoridades indígenas.

Todas las características y obligaciones del cargo de capitán general, se aplican también para el de Kaigi (Gobernador) pues, aunque aparentemente el capitán general está jerárquicamente por encima del gobernador, tal «superioridad» tiene que ver únicamente con cuestiones de representatividad dentro y fuera del territorio indígena, y no así con cuestiones relacionadas con la autoridad inherente al cargo o con la toma de decisiones, las cuales son siempre tomadas a partir del consenso de la comunidad, y no por los sujetos que ocupan estos cargos. En este sentido, los gobernadores son concebidos también como la máxima autoridad indígena en el territorio ódami ${ }^{15}$.

Como ya se señalaba, en cada uno de los pueblos adscritos a Baborigame hay un gobernador (Nabogame, Llano Grande, Cinco Yagas, Santa Rosa, Tuáripa, Coloradas de la Virgen, y desde luego, también en Baborigame), el cual, supuestamente, debe alternarse cada año entre abajeños y arribeños, aunque en realidad sólo en el pueblo de Baborigame es donde se le da mayor importancia a tal prescripción. De igual forma, cada gobernador debe tener - en teoría- un «suplente» o «segundo» abajeño o arribeño - dependiendo el caso- además del resto de «su gente» o «auxiliares». Los gobernadores son elegidos localmente por el consenso de la gente de su pueblo, sin que el capitán general de Baborigame ni nadie más tenga injerencia en tal decisión. Los fiscales y los fiesteros mayores son los encargados de reunir a la gente del pueblo para llegar a un acuerdo sobre el mejor candidato para, posteriormente, invitar al capitán general de Baborigame a asistir al cambio de gobernador (ceremonia que es también realizada en cada uno de los pueblos). Una vez en el cargo, cada gobernador debe preocuparse por asumir las mencionadas funciones de manera local; sin embargo, en el aspecto de la impartición de justicia, los gobernadores de los diferentes pueblos pueden turnar los conflictos considerados muy graves al capitán general de Baborigame, o bien a las autoridades municipales correspondientes (generalmente, el presidente seccional de Baborigame).

15 Según los ódami, el capitán general sólo es un «representante» de los diversos gobernadores de los pueblos de su territorio, pero su voz no «vale más» que la del resto de los gobernadores. Por ejemplo, se dice que el gobernador de Baborigame podría realizar un «juicio» o una «asamblea» sin convocar al capitán general -y viceversa-, aunque ese gesto podría ser visto por la comunidad como una descortesía. 
Figura 2: Ejemplo del sistema de cargos rarámuri de los pueblos de Tuáripa y Coloradas de la Virgen -en territorio ódami-

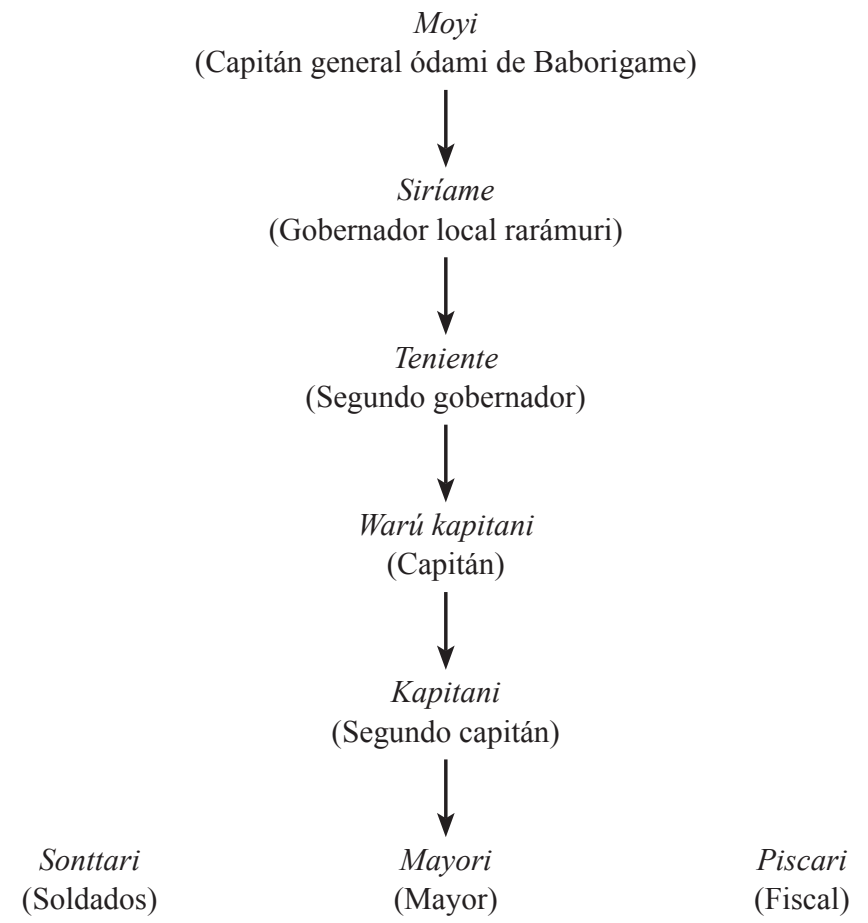

Finalmente, es importante señalar que, aunque el pueblo de Baborigame es concebido por los gobernadores ódami y rarámuri de los pueblos de territorio ódami como el principal centro político-religioso de su territorio, ellos no asisten, salvo en ocasiones excepcionales, a las fiestas o a las asambleas que se realizan en Baborigame, pues su deber es velar por que dichas actividades se realicen adecuadamente en cada uno de los pueblos a los cuales pertenecen.

El Pixskari (Fiscal) es un cargo de participación exclusivamente masculina y ocupado por personas mayores de 30 años. Su duración es variable aunque usualmente es un cargo que se asume por un periodo de tiempo considerable, principalmente por la dificultad de encontrar candidatos que puedan o deseen ocuparlo (en Baborigame, por ejemplo, el actual fiscal lleva más de 26 años ${ }^{16}$. El fiscal debe ser una persona que tenga un profundo conocimiento sobre las fiestas y la tradición indígena. Debe

16 El hecho de encontrar serias dificultades para encontrar a la persona adecuada para ocupar éste y otros cargos del gobierno indígena, es una situación que se repite con frecuencia en distintas comunidades serranas, y que aparentemente se está agudizando en los últimos tiempos. Otro ejemplo de esa situación sería el capitán general de Nabogame, el cual lleva en su cargo más de 16 años debido a que, más allá de su buen o mal desempeño -según las autoridades ódami de Baborigame-, no ha sido substituido debido a que la gente de Nabogame no ha podido todavía encontrar quien pueda o quiera remplazarlo. 
ser alguien que sepa tratar con los fiesteros y los niños de la comunidad, así como ser el interlocutor entre los sacerdotes católicos, las autoridades tradicionales y la comunidad ódami. Sus obligaciones son: cuidar el templo católico y las imágenes de la iglesia -que desde la perspectiva ódami pertenecen a la comunidad-; dar consejos a los jóvenes en distintas reuniones; organizar y dirigir las procesiones del jueves y viernes santo; y cavar, junto con los fiesteros en turno, las fosas para sepultar a los muertos.

Uno de los aspectos más relevantes y singulares del sistema de gobierno ódami es el carácter interétnico a la hora de impartir justicia. El sistema de justicia ódami destaca por el hecho de que sea capaz de juzgar tanto a individuos ódami como rarámuri, siempre y cuando estos últimos pertenezcan a alguno de los pueblos tarahumaras que se encuentran dentro del área de influencia de Baborigame, es decir, Tuáripa o Coloradas de la Virgen ${ }^{17}$.

A los infractores se les juzga siempre tomando en cuenta el lugar donde cometieron la falta de la que se les acusa, y no por su lugar de origen. Por ejemplo, si un sujeto proveniente del pueblo de Llano Grande cometiera alguna infracción en Baborigame que sea causa de juicio, lo juzgarán las autoridades y la gente de Baborigame, y no los de Llano Grande.

De igual forma, líneas arriba hemos señalado que cualquier gobernador tarahumara o tepehuan de alguno de los pueblos adscritos a Baborigame puede, ante una falta que se considere particularmente grave, pedir llevar el caso a Baborigame y solicitar al capitán general que sea él, las autoridades y la gente de ese pueblo las que juzguen el ilícito (lo cual implicaría que el afectado o «quejoso» también debe de ir a Baborigame para exponer su posición ante la comunidad).

Otra característica relevante del sistema de justicia indígena es que, ante alguna falta cometida (peleas, lesiones, robo o daños en propiedad ajena), la queja del denunciante sigue una cadena jerárquica de autoridades hasta llegar al lugar que se considera más indicado para ejercer justicia. Por ejemplo, si en alguna ranchería existe una denuncia por alguna de las infracciones antes mencionadas, se busca, en primera instancia, al comisario de policía del lugar, quien intenta conciliar a las partes y arreglar el problema de manera local ${ }^{18}$. Si el comisario de policía o alguien de los implicados considera que se trata de un problema que no se puede solucionar localmente, se debe buscar directamente al gobernador del pueblo al cual pertenezca la ranchería. Igualmente, en el caso de que éste considere que es un problema «muy pesado» para él, lo turna con el gobernador y el capitán general de Baborigame. Si estos últimos, a su vez, piensan que el problema es también demasiado «pesado» para ellos, lo turnan directamente con el presidente seccional de Baborigame -autoridad no indígena-, quien, dependiendo de la gravedad de la situación, puede o no remitir el asunto con

17 Se dice que mientras sean indígenas, se les puede y se les debe juzgar por igual. En el caso de los no indígenas, no es posible juzgarlos, pues se dice que ellos tienen «sus propias leyes», por lo que lo único que se puede hacer, en el caso de que un mestizo cometa una falta importante en las comunidades indígenas, es correrlo entre todos los del pueblo e ir a presentar una denuncia ante el presidente seccional de Baborigame.

18 Es importante subrayar que ni el comisario de policía, ni nadie que no sea el gobernador o el capitán general, puede impartir justicia. 
las autoridades municipales de Guadalupe y Calvo. Al respecto, ciertas faltas de mayor gravedad, como el homicidio, la violación, el robo o las lesiones agravadas, no siguen la cadena antes descrita, y por lo regular -aunque no siempre- suelen canalizarse directamente con las autoridades no indígenas. Sin embargo, debe subrayarse que existe cierta tendencia a tratar el robo y las lesiones graves a través de las autoridades tradicionales, pues además de que esto da cierta sensación de autonomía a la comunidad, existe una clara desconfianza hacia las autoridades no indígenas, así como una percepción generalizada -alimentada de la experiencia cotidiana- de que son profundamente corruptas y parciales.

\section{El carácter interétnico y etnojerarquizado del sistema de gobierno ódami}

Hemos presentado en el presente texto un panorama general acerca de a la normatividad social y el sistema de gobierno ódami. Hemos destacado dos aspectos singulares, los cuales distinguen notablemente el sistema de gobierno tradicional ódami del de otros pueblos indígenas que habitan el territorio mexicano.

Por un lado, hemos señalado la muy particular territorialidad ódami y su reflejo en el ámbito de acción del sistema de gobierno, la cual se expresa, por ejemplo, en aspectos tales como la división de la comunidad en dos mitades (los abajeños y los arribeños), división que incide directamente en el sistema de cargos, propiciando un equilibrio y una alternancia en la ocupación de los principales puestos del gobierno tradicional. Tal mecanismo tiene también importantes implicaciones en términos de la vida ritual, especialmente en la Semana Santa y las principales ceremonias comunitarias, donde la población indígena (ódami y rarámuri) habitante de este territorio se divide también en esas dos mitades. Una forma de organización ritual que parece ser un elemento distintivo frente a otras formas de organización de los pueblos indígenas del noroeste y el occidente de México ${ }^{19}$ (Saucedo 2008).

Como hemos visto, las características ecológicas de la Sierra Tarahumara y las necesidades económicas de la vida diaria de los indígenas, derivadas de actividades tales como la agricultura, el pastoreo o la recolección, junto con el movimiento necesario para acudir a los distintos ranchos donde se posean tierras, actúan en forma dinámica, creando particulares lazos territoriales (no existe un vínculo con una propiedad basado en la continua ocupación de una familia por muchas generaciones). De esta manera, el territorio ódami puede ser concebido como un mapa imaginario que integra al grupo con el entorno ecológico, el cual abarca la percepción y dimensionalidad que este pueblo le otorga al espacio en que ancestralmente reside, usufructúa y ocupa. Consecuentemente, el territorio étnico no coincide necesariamente con el territorio municipal, ejidal y/o comunal.

19 No obstante, es preciso también señalar que existen algunas comunidades rarámuri (como Cusárare, en el municipio de Guachochi), donde se enuncia explícitamente la distinción entre los de «arriba» y los de «abajo» (Horacio Almanza, comunicación personal). Sin embargo, y a pesar de que es necesario un mayor conocimiento etnográfico sobre el papel que esa división tiene en esta y otras comunidades, parece claro de inicio que dicha partición no tiene la misma importancia ritual y política que posee para los ódami. 
A partir de esta primera singularidad, siendo el aspecto fundamental del texto, hemos resaltado el carácter interétnico y etnojerarquizado del sistema de gobierno, lo cual constituye un rasgo único en el contexto de los pueblos indios del norte de México, y también entre muchos otros pueblos de tradición mesoamericana. El carácter interétnico del sistema de gobierno ódami queda de manifiesto al observar que su sistema de cargos integra, bajo la figura del capitán general de Baborigame (un cargo que no existe en ningún otro pueblo de la Sierra Tarahumara, y que posiblemente deriva de la organización para la resistencia a la colonización, a semejanza de los yaquis en Sonora), a los ya mencionados siete pueblos que constituyen su territorio: cinco de ellos habitados por población ódami y dos más por población rarámuri. Al respecto, insistimos en que cada uno de esos pueblos posee su propio gobernador, a quien se considera la máxima autoridad local, y por lo tanto, quien preside las asambleas del gobierno tradicional, los juicios, y las principales ceremonias religiosas. No obstante, cada uno de los siete gobernadores de esos pueblos, y la comunidad a la que representan, reconoce que el capitán general de Baborigame es la máxima figura de autoridad y representatividad indígena dentro de su territorio, al grado de que, por ejemplo, ninguno de estos siete pueblos pueden hacer la elección y cambio de su nuevo gobernador sin la presencia del Moyi o capitán general de Baborigame.

No teniendo referencia hasta ahora de un caso similar -al menos en el contexto mexicano-, en el cual un pueblo indígena reconozca abiertamente su subordinación ante los principales cargos del gobierno de otro pueblo étnicamente distinto, pensamos que éste es precisamente uno de los aspectos que requieren un análisis más exhaustivo, el cual incluya, por ejemplo, la propia perspectiva rarámuri del sistema, sobre la cual, actualmente, no se tiene datos de relevancia. Finalmente, el texto ha querido ser un llamamiento a la necesidad de profundizar en los estudios de los pueblos indígenas del norte de México.

\section{Referencias bibliográficas}

Aguirre Beltrán, Gonzalo

1953 Formas de gobierno indígena. México: Imprenta Universitaria.

1967 Regiones de refugio. México: Instituto Indigenista Interamericano.

BRANIFF, Beatriz

1999 «La Gran Chichimeca». Arqueología Mexicana 51: 40-45.

2000a «La frontera Septentrional de Mesoamérica», en Historia Antigua de México. El México antiguo, sus áreas culturales, los origenes y el horizonte Preclásico, vol. 1, Linda Manzanilla y Leonardo López Luján, ed., pp. 159-190. México: CNCA UNAM - Porrúa.

2000b «Sistemas agrícolas prehispánicos en la Gran Chichimeca», en Nómadas y Sedentarios en el Norte de México: Homenaje a Beatriz Braniff, Marie-Areti Hers et al., ed., pp. 127-142. México: UNAM - IIE - IIH - IIA.

BYE, Robert

1976 The Ethnoecology of the Tarahumara of Chihuahua. Tesis doctoral. México: Harvard University. 
CANCIAN, Frank

1966 «Algunos aspectos de la organización social y religiosa de una sociedad maya», en Los zinacatencos, E. Z. Vogt, ed., pp. 315-326. México: SEP - INI.

1989 Economía y prestigio en una comunidad maya. México: CNCA/INI.

1996 «Instituciones políticas y religiosas», en Introducción al sistema de cargos, Leif Korsbaek, ed. Toluca: Universidad Autónoma del Estado de México.

CARrasco, Pedro

1990 «Sobre el origen histórico de la jerarquía político-ceremonial de las comunidades indígenas», en Historia, Antropología y política. Homenaje a Ángel Palerm, vol. I, M. Suárez, coord., pp. 306-326. México: Alianza Editorial.

Castilleja, Aída y Gabriela Cervera

2003 «La comunidad y el costumbre en la región purépecha», en La comunidad sin límites. La estructura social y comunitaria de los pueblos indígenas de México, vol. III, S. Millán y J. Valle, coords., pp. 17-112. México: CONACULTA - INAH.

Chance, John y William B. TAYlor

1987 «Cofradías y cargos: una perspectiva histórica de la jerarquía cívico-religiosa mesoamericana». Antropología, Boletín Oficial del INAH 14.

Di Peso, Charles

1974 Casas grandes. A Fallen Trading Center of the Gran Chichimeca, Flagstaff: The Amerind Foundation - Northland Press.

GonZÁLEZ, Íñigo

s/f «El sistema de cargos en una sociedad local urbanizada, industrializada y mestiza: Nativitas, Tlaxcala», en Cambio social y formación de nuevas ruralidades, Hernán Salas et al., ed. México D.F.: IIA - UNAM.

GONZÁLEZ R., Luis

1991 Tarahumara 1626-1724. Chihuahua: Camino.

GonzÁlez R., Luis, Susana Gutiérrez, Paola Stefani, Margarita Urías y Augusto Urteaga 1994 Derechos culturales y derechos indigenas en la Sierra Tarahumara. Estudios Regionales, 8. Ciudad Juárez: Universidad Autónoma de Ciudad Juárez.

GreenberG, James B.

1987 Economía y religión entre los chatinos. México: INI.

Hillerkuss, Thomas

1992 «Ecología, economía y orden social de los tarahumaras en la época prehispánica y colonial». Estudios de Historia Novohispana 12: 9-62.

JÁUREGUI, Jesús (coord.),

2003 «La autoridad de los antepasados, ¿un sistema de organización social de tradición aborigen entre los coras y los huicholes?», en La comunidad sin límites. La estructura social y comunitaria de los pueblos indígenas de México, S. Millán y J. Valle (coords.), vol. III, pp. 113-216. México: Conaculta - INAH. 
JÁuREGui, Jesús

2005 «La etnografía sobre el área septentrional del Gran Nayar: Indígenas de Durango, Nayarit y Jalisco (tepehuanes del sur, mexicaneros y tepecanos)», en Las Regiones indígenas en el espejo bibliográfico. Bibliografía comentada, J. Jáuregui y A. Castilleja, eds., pp. 203-305. México: INAH.

KenNedy, John G.

1970 Inápuchi: una comunidad tarahumara gentil. México: Instituto Indigenista Interamericano.

KorsBAEK, Leif

1996 Introducción al sistema de cargos. Toluca: UAEM.

LÉvi-Strauss, Claude

1995 «Existen las organizaciones dualistas?», en Antropología estructural, pp. 119148. Barcelona: Paidós.

Lumholtz, Carl S.

1981 El México desconocido. México: INI.

Mason, John

1948 «The Tepehuan and the other Aborigines of the Mexican Sierra Madre Occidental». América Indígena 8 (4): 289-300.

Medina, Andrés

1995 «Los sistemas de cargos en la Cuenca de México: una primera aproximación a su trasfondo histórico». Alteridades 9: 7-23.

Molinari, Claudia y Eusebio Nolasco

1995 «Los tepehuanos del norte», en Etnografía Contemporánea de los Pueblos Indigenas de México: Noroeste, pp. 485-528. México: INI.

PACHeCO, Carl S.

1997 Misión y educación: los jesuitas en Durango 1596-1767. Tesis doctoral. México: Colegio de México.

Pennington, Campbell W.

1969 The Tepehuan of Chihuahua: Their Material Culture. Salt Lake City: University of Utah Press.

Reyes, Antonio

2004 Pimas, pápagos y tepehuanes. Relaciones lengua-cultura entre los pueblos tepimanos del noroeste de México y el suroeste de los Estados Unidos. Tesis de maestría. México: UNAM.

Romero, Osvaldo

2002 La Malinche. Poder y religión en la región del Volcán. Tlaxcala: Universidad Autónoma de Tlaxcala.

SANDOval, Eduardo A.

2000 «Sistema cultural-jurídico y sistema de cargos en los mazahuas». Cuicuilco, 7 (19): 103-116. 
SAUCEDO, Eduardo R.

2003 «Reciprocidad y vida social en la Tarahumara. El complejo tesgüino y los grupos del sur de la sierra», en La comunidad sin límites. La estructura social y comunitaria de los pueblos indígenas de México, vol. III, S. Millán y J. Valle, coords., pp. 217-267. México: CONACULTA - INAH.

2005 Tepehuanes del norte, México. México: CDI - PNUD.

2007 «Notas y reflexiones etnográficas en torno a la fauna y su relación con la región celeste del cosmos rarámuri». Cuicuilco 14 (39): 79-98.

2008 «El sistema de organización de mitades en la Semana Santa ódami en el pueblo de Baborigame». Tierra Norte. Revista de la Escuela Nacional de Antropología e Historia-Unidad Chihuahua 4.

$\mathrm{s} / \mathrm{f} \quad$ «Notas sobre la cultura y la cosmovisión ódami».

SAucedo, Eduardo R. y Eugeni Porras

2005 «Identidades y relaciones interétnicas en la Tarahumara», en Etnografía de las Regiones Indígenas de México en el Nuevo Milenio. Relaciones interétnicas e identidades indígenas en el México actual, Vol. I. México: INAH.

SERRANO, Enrique (coord.)

2006 Regiones indigenas de México. México: CDI - PNUD.

SCHMIDT, Robert

1976 A Geographical Survey of Chihuahua. Southwestern Studies, 37. El Paso: Texas Western Press.

Smith, Waldemar R.

1981 El sistema de fiestas y el cambio económico. México: Fondo de Cultura Económica.

Velasco, Pedro

1983 Danzar o morir: religión y resistencia a la dominación en la cultura tarahumar. Chihuahua: Centro de Reflexión Teológica. 